\title{
Lymphoproliferative response as an index of cellular immunity in malignant melanoma of the uvea and its correlation with the histological features of the tumour
}

\author{
M. S. NOOR SUNBA, ${ }^{1}$ A. H. S. RAHI, G. MORGAN, AND \\ E. J. HOLBOROW' \\ From the ${ }^{1}$ Department of Pathology, Institute of Ophthalmology, University of London, \\ and the ${ }^{2}$ Bone and Joint Disease Research Unit, The London Hospital
}

SUMMARY Cell-mediated immunity and immune complexes were studied in 22 cases of malignant melanoma of the choroid and in 3 patients with iris melanoma. An attempt has been made for the first time to correlate the cell-mediated immunological changes with the histological features of the tumour and the extent of the disease. In most of the patients the lymphoblastic response to tuberculin and phytohaemagglutinin was within normal range, indicating that there is no obvious suppression of $\mathrm{T}$ lymphocyte-dependent immunity in intraocular melanoma. However, only about half the patients showed an increased lymphoproliferative response to their own tumour antigens or to pooled allogeneic melanoma extracts. The response to the latter was invariably weaker, suggesting that although melanoma antigens may show cross-reactivity there exists an element of individual specificity. As the transformation index was generally low (i.e., $\bumpeq 3$ ) it is tempting to conclude that uveal melanomas are either poorly immunogenic or that the immune system is insufficiently stimulated when the tumour is confined within the eye ball. The latter would seem more likely. Although the lymphocyte transformation test appears to be unreliable in the early diagnosis of intraocular melanoma, it promises to be useful in the prognosis of this tumour. The host immune system appears to be better stimulated if the tumour is large and contains a detectable proportion of epithelioid cells. Histochemical and ultrastructural examination of the lymphocytes infiltrating the tumour showed evidence of cytoplasmic activation, suggesting that these cells may be actively engaged in tumour homoeostasis. With one exception Clq-binding immune complexes were not raised in the blood of the patients examined so that tumour-enhancement (through this mechanism at least) may not be an important feature in the natural history of intraocular melanoma.

Interest in the natural history of malignant melanoma of the uvea and in the existence of a host defence mechanism has been stimulated by the observation that uveal melanomas may remain localised for long periods-over 30 years in 1 case. $^{1}$ It is also known that malignant melanomas of the iris rarely metastasise, ${ }^{23}$ while some intraocular melanomas may even undergo spontaneous regression. ${ }^{4}$ In an attempt to explain this puzzling behaviour of some uveal melanomas several hypotheses have been put forward, such as the effects of the host environment, ${ }^{6}$ defensive substances, ${ }^{7}$ bio-

Correspondence to Dr A. H. S. Rahi, Institute of Ophthalmology, Judd Street, London WC1H 9QS. chemical barriers, ${ }^{8}$ and specific immune

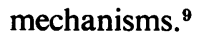

Although much of the antigenicity of tumour extracts is attributable to components shared with non-neoplastic cells, there are also antigens which are peculiar to tumour cells in general and uveal melanoma in particular. ${ }^{9}$ These tumour-associated antigens are conveniently divided into 2 categories: those associated with the surface membrane and those linked with the intracytoplasmic contents. The surface membrane antigens can initiate a transplantation rejection process, so that these antigens have also been called tumour-specific transplantation antigens. Both surface and intracytoplasmic tumour-associated antigens have been 


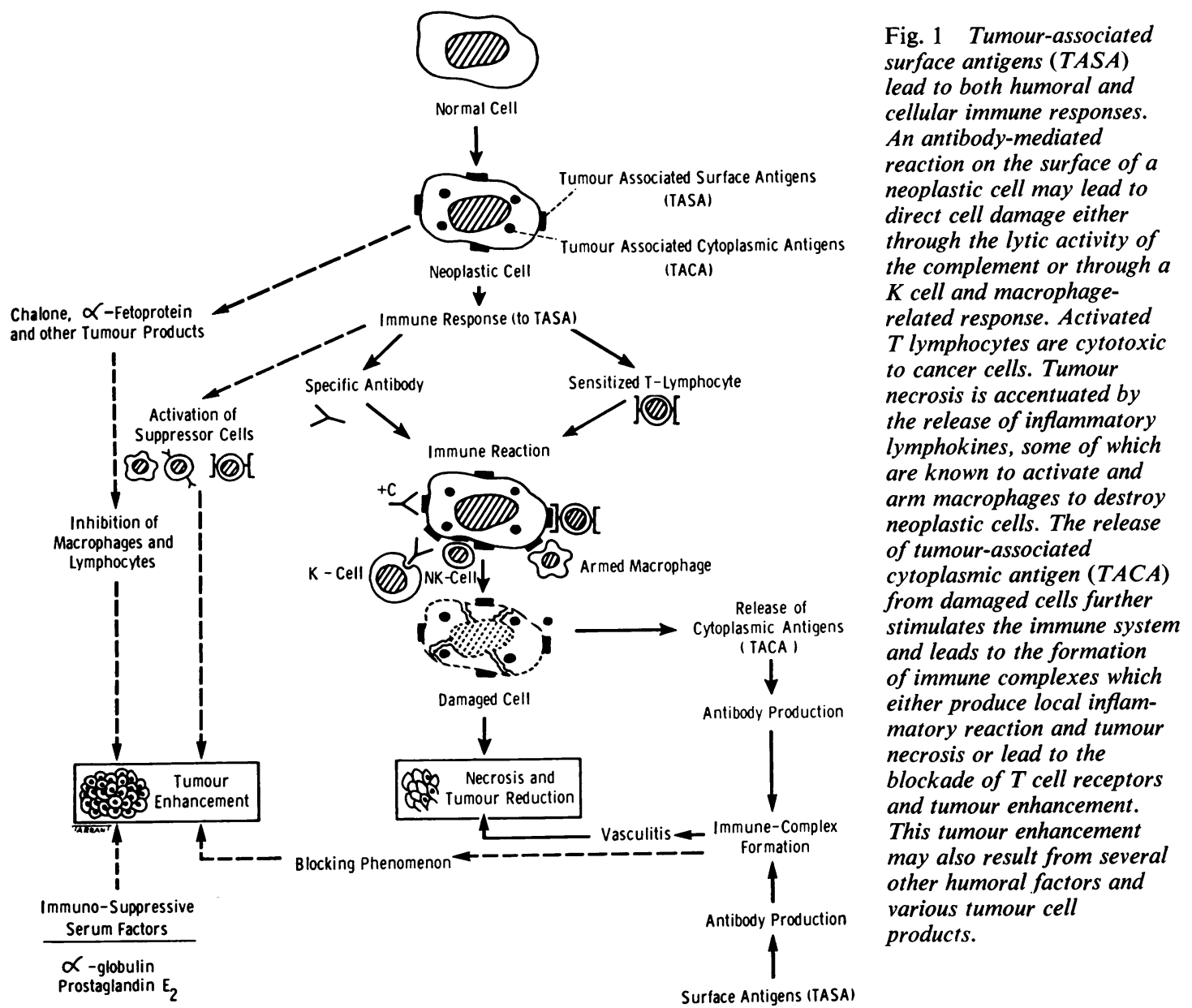

described in malignant melanoma of the choroid, ${ }^{9} 10$ and it would seem that, whereas there is a considerable sharing of intracytoplasmic tumour antigens between one uveal melanoma and another, most surface antigens are peculiar to an individual tumour. It is possible, however, that melanomas of the uvea may resemble those of the skin in having 2 additional types of surface antigens: one being specific to melanoma cells but common to a number of individual tumours (histotype-specific) and the other shared with neoplastic and non-neoplastic tissues in a number of species. ${ }^{11-13}$ Since antibodies do not penetrate intact cell membranes, the role of cytoplasmic antigens in stimulating an effective host defence mechanism is questionable. Conversely antibodies to surface membrane antigens appear to be cytotoxic to uveal melanoma cells in short-term tissue culture studies ${ }^{14}$ and are more likely to be involved in host immunity. It is now accepted that, as with graft rejection, the control of tumour growth is mainly executed by $\mathrm{T}$ lymphocytes, which differ from antibody in not requiring complement to exert cytotoxic activity and in being able to penetrate solid tissues (Fig. 1). Delayed cutaneous hypersensitivity to soluble extracts of melanoma cells have been studied in patients with intraocular malignant melanoma. ${ }^{15}$ Although the majority of the patients tested showed a positive skin reaction to the test antigen, the reaction was negative in a significant proportion of histologically confirmed patients, and false positive results were obtained in about $20 \%$ of patients with benign or nonneoplastic intraocular lesions.

Although the skin test appears to correlate well with cellular immunity, particularly against infective organisms, the expression of skin reactivity itself 
depends not only on the infiltrating $\mathrm{T}$ lymphocyte but also on the vasculature and the microanatomy of the test site and the capacity of an individual to mount a nonspecific inflammatory response following injury. ${ }^{16}$ To overcome these in-vivo limitations it has been suggested that in-vitro tests should be carried out. Manor and co-workers ${ }^{17}$ therefore studied direct (i.e., 1-stage) macrophage migration inhibition tests in patients with uveal melanoma in which a crude extract obtained from 4 allogeneic (i.e., homologous) intraocular melanomas were used as a source of antigen. This test seemed to provide good discrimination between malignant and benign pigmented tumours. However, its specificity as an indicator of cellular immunity is now being questioned because tissue extracts may either be cytotoxic to leucocytes and cause nonspecific migration inhibition or contain other substances such as antibodies which may alter the cell membrane of these cells and inhibit their movement. ${ }^{18}$ It has been suggested, therefore, that indirect (i.e., 2-stage) migration inhibition assays (in which the macrophages are incubated with the supernate obtained from a culture of patients' lymphocytes incubated separately with the test antigen) should provide more reliable results. ${ }^{19}$

Cell-mediated immunity in malignant tumours including those of the uvea has also been studied by a macrophage electrophoretic mobility (MEM) test. ${ }^{2021}$ The technique is based on the concept that lymphocytes from patients with cancer are sensitised to a basic protein present in human brain and cancer cells. When incubated with this antigen, the sensitised lymphocytes release a macrophageslowing factor which can be detected by its effect on the electrophoretic mobility of guinea-pig macrophages. This technique differs from the conventional macrophage migration inhibition test in that in the MEM test it is the passive movement rather than the active migration which is grossly affected. Although the validity of this in-vitro blood test has been confirmed, ${ }^{22}{ }^{23}$ several other workers, including ourselves, have been unable to do so and found that technical limitations which make standardisation difficult render the test of little value. ${ }^{2124-26}$

Malignant melanoma of the uvea can pose diagnostic problems despite the development of such sophisticated techniques as fluorescein angiography, the ${ }^{32} \mathrm{P}$ test, and ultrasonography. A mistaken diagnosis of malignancy is more common in small tumours of the uvea, ${ }^{27}$ and the incidence of unnecessary enucleation may be as high as $20 \% .{ }^{28-30}$ Because of this there is a considerable incentive to develop a reliable technique for the preoperative diagnosis of malignant melanoma.

The serological diagnosis of an intraocular malignant melanoma appears to be difficult because of the presence of ostensible antimelanoma antibodies in patients with non-neoplastic eye disease, ${ }^{1213}$ and it seems unlikely that antibodies alone are responsible for tumour homoeostasis. We decided, therefore, to investigate other parameters of host immunity to tumours. Since skin tests, leucocyte migration inhibition tests, and macrophage electrophoretic mobility tests have been carried out with variable success in the diagnosis of intraocular malignancy, and it has been reported that the lymphocyte transformation test using radioactive thymidine is easy to quantitate and correlates well with the extent of the disease in relation to malignant melanoma of the skin, ${ }^{31}$ we have attempted to evaluate the usefulness of the latter test as an immunodiagnostic procedure.

\section{Methods and materials}

Fresh tumour cells obtained from enucleated eyes were homogenised in sterile phosphate-buffered saline ( $\mathrm{pH} \mathrm{7.4)}$ with a pestle and mortar and then transferred to an electrical blender for further homogenisation. The suspension was centrifuged at $2000 \mathrm{~g}$ for 10 minutes to remove cellular debris, nuclei, and melanin pigment. It was then dialysed against phosphate-buffered saline (pH 7.4) for 24 hours at $4^{\circ} \mathrm{C}$ and stored in liquid nitrogen until used. Antigenic extracts were also prepared using hypertonic potassium chloride solution as originally described by Meltzer et al. $^{32}$ The cell suspension obtained from minced tumour material was suspended in $20 \mathrm{ml}$ of $3 \mathrm{M} \mathrm{KCl}(\mathrm{pH} \mathrm{7.4})$ and left at $4{ }^{\circ} \mathrm{C}$ for 24 hours with frequent shaking. The suspension was centrifuged at $40000 \mathrm{~g}$ for 60 minutes and the supernate was dialysed for 16 hours against phosphate-buffered saline (pH 7.4). The dialysed material was centrifuged again at $40000 \mathrm{~g}$ for 15 minutes. The supernatant was concentrated by using Lyphogel and sterilised by passing the solution through a Millipore filter $(0.22 \mu \mathrm{m})$. The protein concentration was estimated by a modified Lowry method. ${ }^{33}$

\section{LYMPHOCYTE CULTURE}

Blood was collected before enucleation in preservative-free heparin (20 units per $\mathrm{ml}$ ) and lymphocytes were separated by a density-gradient technique using a Ficoll-Hypaque preparation (Pharmacia). After the viability of lymphocytes had been tested by the trypan blue technique they were cultured in medium 199, each millilitre of which contained 200 units of penicillin and $100 \mu \mathrm{g}$ of streptomycin. The medium was enriched immediately before use by 
the addition of the patient's own serum $(1: 10)$ and freshly prepared glutamine $(2 \mathrm{mmol} / \mathrm{ml})$. The test was carried out in Sterilin tubes in a gaseous phase of $5 \%$ carbon dioxide in air; $10^{6}$ lymphocytes suspended in $1 \mathrm{ml}$ of the enriched nutrient medium were put in each tube. In an initial study various concentrations of the crude preparation as well as potassium chloride extracted antigens were used to obtain a dose-response curve. Suitable amounts of both autochthonous (i.e., autologous) and pooled allogeneic (i.e., homologous) antigen preparations were added separately to the various culture tubes 24 hours after the initial incubation of the lymphocytes, during which time the suppressor lymphocytes appear to become less effective and do not grossly interfere with the lymphoproliferative response of antigen-sensitive lymphocytes (Brostoff, personal communication). In order to study the state of cellular immunity in general, the lymphocytes from patients with malignant melanoma of the uvea were also cultured with various concentrations of specific and non-specific mitogens such as purified protein derivative (PPD) and phytohaemagglutinin (PHA). Controls to exclude a possible mitogenic effect of normal human choroid were set up and the various tests were carried out in duplicate.

In order to study the specificity of this test melanoma antigens were also added to the lymphocyte from healthy individuals, from patients with nonmalignant eye diseases, including disciform macular degeneration, sympathetic ophthalmitis, melanocytoma (magnocellular naevus) of the ciliary body, and naevus of the iris, and also from a case of carcinoma of lung with metastases in the choroid. $2 \mu \mathrm{Ci}$ of tritiated thymidine (specific activity $20 \mathrm{Ci}$ / mmol) were added to each control and the experimental tubes on the 6th day of the experiment, and incubated for a further period of 16 hours. The lymphocytes were then harvested by centrifugation; the supernatant was deep frozen and studied later for evidence of lymphokine production. The lymphocytes were resuspended in phosphate-buffered saline and passed through a specially designed funnel containing fibreglass filter paper. They were washed with $5 \mathrm{ml}$ of $10 \%$ trichloroacetic acid and $20 \mathrm{ml}$ methanol. The filter paper was transferred to scintillation vials and dried in an oven at $37^{\circ} \mathrm{C}$ for 3 hours; $10 \mathrm{ml}$ of toluene-based scintillation fluid was added to each vial, and the lymphoproliferative response was measured in terms of ${ }^{3} \mathrm{H}$ thymidine uptake (for DNA synthesis) in a Packard tricarb liquid-scintillation counter. The disintegration was expressed in counts per minute. To obtain the transformation index the count in the vial containing antigen-treated cells was divided by the radioactivity in that containing unstimulated cells.
INDIRECT MACROPHAGE MIGRATION

INHIBITION TEST

Macrophages were obtained from adult male Hartley guinea-pigs 6 days after the injection of $25 \mathrm{ml}$ of sterile liquid paraffin into the peritoneum. Heparinised Hanks's fluid was injected into the peritoneal cavity, and the macrophage-rich suspension was aspirated with a $20 \mathrm{ml}$ syringe attached to a perforated polypropylene tube, care being taken not to traumatise the tissues. The cell suspension was passed through a separating funnel, spun at $250 \mathrm{~g}$ for 10 minutes, and resuspended in medium 199. The concentration was : diusted to $8 \times 10^{6}$ cells per millilitre of the medium, $v$.hich was enriched with normal guinea-pig serum. The indirect (i.e., 2-stage) inhibition studies were carried out in specially designed Sterilin chambers. During the study it was found that Plasticine used to seal the capillary tubes produced nonspecific inhibition of macrophages, and therefore a small amount of sterile silicon gel was introduced into the capillary tube to separate the macrophage column from the Plasticine. The cells were incubated in the supernatant obtained from the unstimulated culture, and the area of migration was compared with those in supernatants from antigen-treated cells. Supernatant from antigen-treated lymphocyte cultures from healthy individuals was also used in a separate study to exclude any nonspecific inhibitory effect of melanoma extract.

Migration inhibition of more than $25 \%$ giving an index of less than 0.75 , was regarded as abnormal for the present study.

\section{IMMUNE-COMPLEX ESTIMATION}

It has been shown that a tumour may sometimes show a marked increase in size in the presence of an apparent immune response. This is known as tumour enhancement, and it is now considered to be due to blocking of antigen-specific receptors on $T$ lymphocytes by free tumour antigens or antigenantibody complexes. ${ }^{34}$ It is possible, therefore, that the in-vitro lymphoproliferative responses to tumour antigens may also be modified by the presence of antigen-antibody aggregates in the patients' serum. ${ }^{35}$ Sera from melanoma patients was investigated, therefore, for the presence of soluble immunecomplexes using an ${ }^{125} \mathrm{I}-\mathrm{Clq}$ binding assay. $\mathrm{Clq}$ was isolated from normal human serum and radioiodinated by the lactoperoxidase method. Fixed amounts of radiolabelled Clq were added to the test serum, and the complexes were precipitated with $3 \%(w / v)$ polyethylene glycol (PEG). The mixture was centrifuged at $1500 \mathrm{~g}$ for 20 minutes at $4^{\circ} \mathrm{C}$, the supernatant was discarded, and the radioactivity of the precipitate was measured. Results were expres- 
sed as a percentage of ${ }^{125} \mathrm{I}-\mathrm{Clq}$ precipitate relative to the radioactivity in the control tube in which normal serum containing the same amount of radiolabelled $\mathrm{Clq}$ is precipitated with $20 \%$ trichloroacetic acid (TCA). Blood from 50 healthy adults and 52 cases with various eye diseases was also tested for immune complexes, and the data obtained were used for comparison and statistical analysis. In the present study only those samples that showed ${ }^{125} \mathrm{I}-\mathrm{Clq}$ binding of $12 \%$ or over were regarded as abnormal and were considered to contain raised levels of immune complexes.

\section{HISTOLOGICAL EXAMINATION}

After removal of part of the tumour for immunological studies the enucleated eyes were fixed in buffered formol saline, and paraffin sections were stained with haematoxylin and eosin and methyl green and pyronine $\mathrm{Y}$ for histological examination. The sections were bleached in cases where the pigment content made it difficult to assess the cell type. The largest diameter of the tumour in contact with the sclera was measured in millimetres. The sections were also examined for evidence of necrosis, lymphocytic infiltration, immunoblastic transformation (i.e., pyroninophilia), and extraocular extension. A portion of the tumour was first fixed in gluteraldehyde and then in osmium tetroxide and blocked in Araldite for electron microscopical examination. The sections were stained with lead citrate and uranyl acetate and examined with a JOEL $100 \mathrm{C}$ transmission electron microscope. Statistical analysis of the immunological investigations was carried out by Fisher's exact test.

\section{Results}

A transformation index of 2 or more was regarded as evidence of sensitisation to tumour antigens. The lymphocyte transformation test using autochthanous (i.e., autologus) tumour extract was performed in only 19 of the 22 cases of malignant melanoma of the choroid because enucleation was not undertaken in the other 3 cases. An increased lymphoproliferative response was seen in 10 cases (Table 1). The response to allogeneic tumour antigen, however, was weaker than that incurred by autologous tumour extract. In general, the response to $\mathrm{KC1}$ extracted antigen was marginally stronger than that to the crude antigen preparation. There was also a wide variation in the response to PPD and PHA, but with the exception of 5 cases (see Tables 1 and 3) the transformation index was generally within the normal range (that is, $>12$ for PHA).

Generally it was found that patients who showed marked reactivity towards PPD and PHA also showed a response to tumour antigens. It can be argued that a generally low uptake of radioactivity in our experiment was due to the fact that ${ }^{3} \mathrm{H}$ thymidine of a high specific activity $(20 \mathrm{Ci} / \mathrm{mmol})$ was used, since this might have damaged some of the lymphocytes. We have used, however, the same isotope with a low specific activity, i.e., $2 \mathrm{Ci} / \mathrm{mmol}$ in 6 cases without any marked changes in the lymphoproliferative response. The lymphoproliferative response to normal human choroidal extract was studied in only 9 patients, and the transformation index in these cases was always $<2$. This is in keeping with the previous report in which it was shown that antimelanoma antibodies do not crossreact with normal choroid. ${ }^{36}$

The lymphocyte transformation test was carried out in only 3 cases of malignant melanoma of the iris; autochthonous (autologous) tumour antigen was used in 2 patients, and a high thymidine uptake was present in both cases (Table 2). The reactivity towards allogeneic tumour was weaker, and in only 1 case was there an appreciable increase in the DNA synthesis. The response to PHA was within the normal range in 2 of the 3 cases examined.

The lymphoproliferative response to allogeneic melanoma extract was minimal or negligible in healthy controls as well as in patients with clinically benign lesions, secondary carcinoma of the choroid, and in non-neoplastic eye disease. The response to PHA in most of these cases was normal (Table 3). The statistical analysis of the lymphoproliferative response and its correlation with various histological parameters are summarised in Table 4.

In cases where the lymphocyte transformation test was positive (Table 1) it was found that the tumour was generally large $(P<0.001)$, the largest diameter in contact with the sclera being $12 \mathrm{~mm}$ or over, though there was 1 exception in which a tumour with a diameter of $15 \mathrm{~mm}$ showed a transformation index with autochthonous tumour extract of less than 2. In the case of iris melanoma a positive response was associated with a diffuse infiltrating tumour.

Extraocular extension was evident in 6 cases of malignant melanoma of the choroid and in 1 patient with iris melanoma. The lymphocyte transformation test was positive in all of them $(P<0.001)$.

In only 1 case was the tumour of epithelioid cell type, 8 cases were of mixed variety, and the rest were composed almost exclusively of spindle cells. The lymphoproliferative response was increased only in patients with a mixed-cell type of melanoma $(\mathrm{P}<\mathbf{0 . 0 0 1 )}$.

Pigmentation was heavy in 4 cases, moderate in another 6 , and light in the rest. There was no corre- 

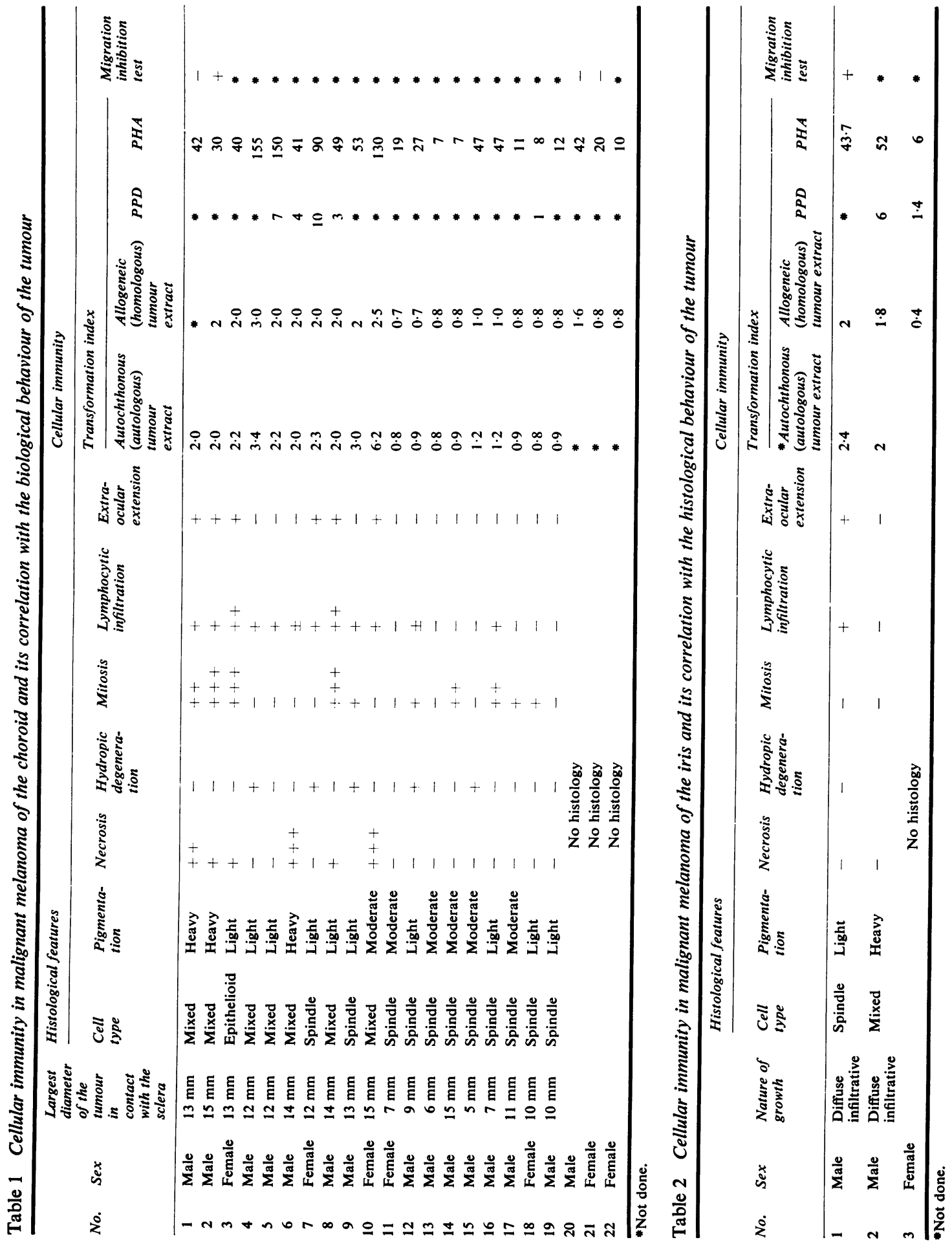
Table 3 Lymphoproliferative response to melanoma antigens in the control group

\begin{tabular}{|c|c|c|c|c|}
\hline \multirow[b]{3}{*}{ No. } & \multirow[b]{3}{*}{ Sex } & \multirow[b]{3}{*}{ Nature of lesion } & \multirow{2}{*}{\multicolumn{2}{|c|}{$\frac{\text { Cellular immunity }}{\text { Transformation index }}$}} \\
\hline & & & & \\
\hline & & & $\begin{array}{l}\text { Allogeneic } \\
\text { (homologous) } \\
\text { tumour } \\
\text { extract }\end{array}$ & $P H A$ \\
\hline 1 & Male & $\begin{array}{l}\text { Disciform macular } \\
\text { degeneration }\end{array}$ & 0.96 & 50 \\
\hline 2 & Female & Sympathetic ophthalmitis & $1 \cdot 0$ & 34 \\
\hline 3 & Male & Lepromatous iritis & $1 \cdot 0$ & 27 \\
\hline 4 & Male & $\begin{array}{l}\text { Melanocytoma of the } \\
\text { CB (magnocellular } \\
\text { naevus) }\end{array}$ & 0.93 & 20 \\
\hline 5 & Male & Iris naevus & 0.8 & 13 \\
\hline 6 & Male & $\begin{array}{l}\text { "Lung carcinoma with } \\
\text { choroidal metastases }\end{array}$ & 0.9 & 34 \\
\hline 7 & Male & $\begin{array}{l}\text { * Metastatic adenocar- } \\
\text { cinoma (choroidal) }\end{array}$ & 0.84 & $4 \cdot 7$ \\
\hline 8 & Male & Healthy control & $1 \cdot 1$ & 28 \\
\hline 9 & Male & Healthy control & 1 & 39 \\
\hline 10 & Male & Healthy control & 1 & 60 \\
\hline 11 & Male & Healthy control & 1 & 47 \\
\hline 12 & Male & Healthy control & $1 \cdot 2$ & 40 \\
\hline
\end{tabular}

lation between the degree of pigmentation and the lymphoproliferative response.

Distinct apoptosis and coagulative necrosis were evident in 6 cases and absent in the remaining 15 cases. The tumour-specific immune response appeared to correlate well with the extent of necrosis $(\mathbf{P}<\mathbf{0 . 0 0 1 )}$.

Lymphocytic infiltration (Fig. 2) was extensive in 2 cases, prominent in 8 cases, and occasional in 2 cases. The remaining 9 cases did not show any round cell infiltration in the sections examined. Methyl green pyronine $Y$ staining showed the presence of occasional immunoblasts among the infiltrating lymphocytes, thus providing direct evidence of in-vivo activation of these cells. Electron microscopic examination complemented this finding and revealed the presence of lymphocytes with well developed rough endoplasmic reticulum and prominent mitochondria (Fig. 3).

Mitotic activity was markedly increased in 3 cases, all of which had a positive lymphoproliferative response. A moderate to low activity was seen in 7 patients, and the test was positive in only 2 patients. The mitotic activity does not appear to correlate with the degree of blastic response.

${ }^{125} \mathrm{I}-\mathrm{Clq}$ binding assay was carried out in 22 cases of malignant melanoma of the choroid and 3 cases of iris melanoma and the results were com-

Table 4 Tumour-specific immunity in malignant melanoma of the uvea: analysis of significance

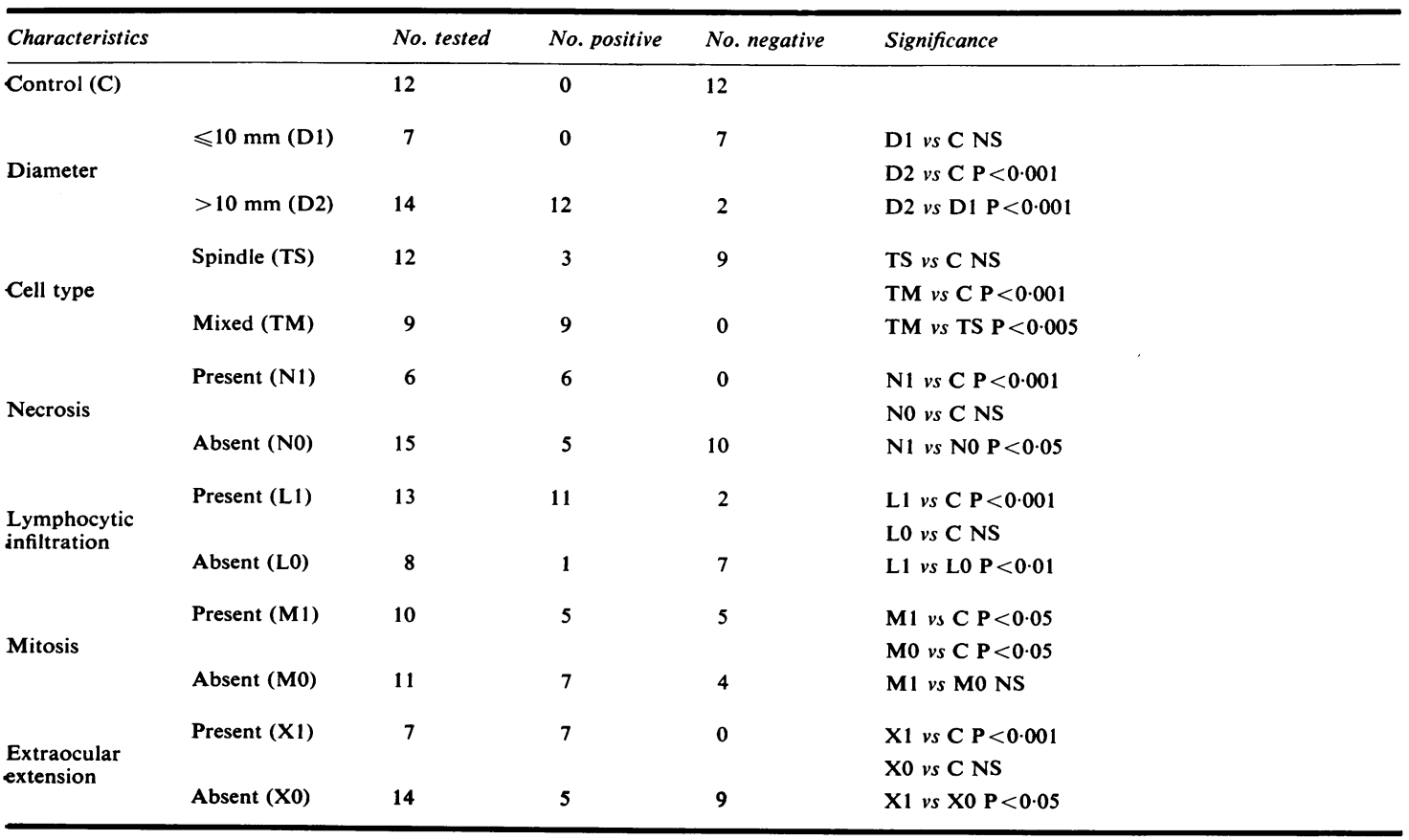



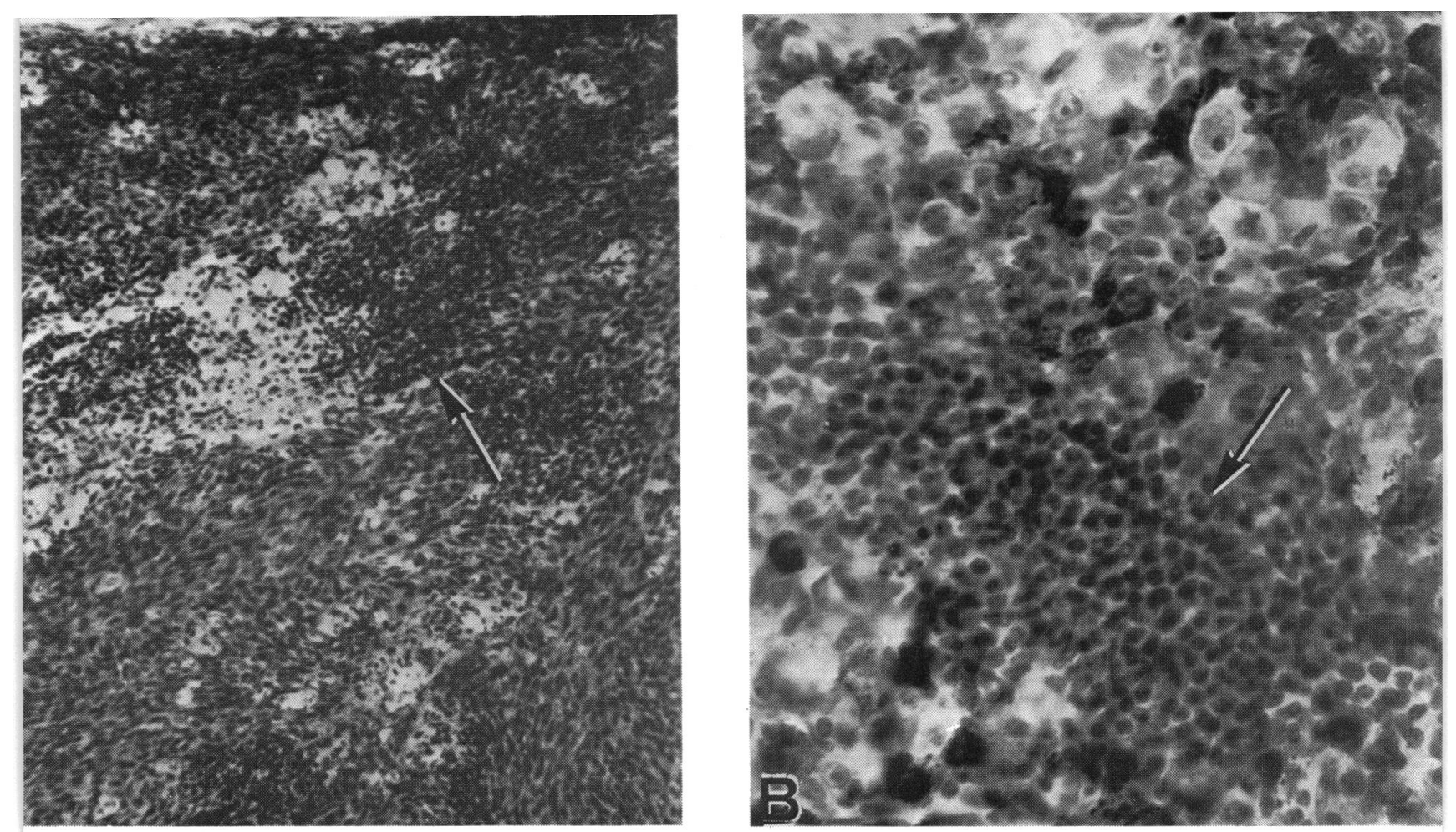

Fig. 2 Section of a malignant melanoma of the choroid showing lymphocytic infiltration. A: Spindle cell melanoma. ( $H$ and $E, \times 185)$. B: Mixed cell melanoma. $(H$ and $E, \times 590)$.

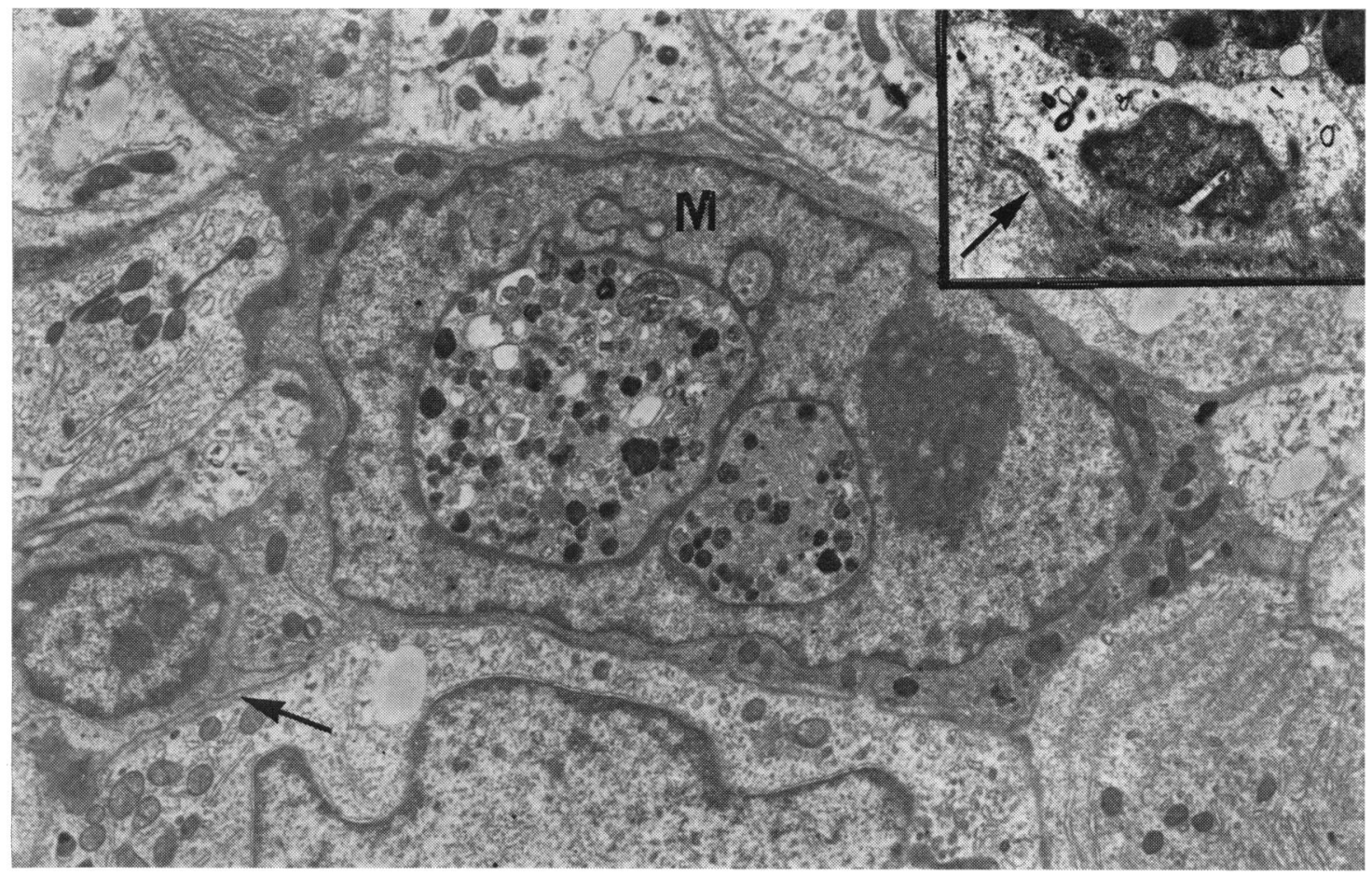

Fig. 3 Transmission electron micrograph showing a melanoma cell $(M)$ with an intranuclear cytoplasmic inclusion. The adjacent cell is a lymphocyte $(\times 10670)$. The inset shows an activated lymphocyte with a cleaved nucleus and abundant cytoplasm containing ribosomes $(\times 6400)$. 
Table 5 Immune complexes in the blood from patients with malignant melanoma of the uvea $\left({ }^{125} \mathrm{I} \mathrm{Clq}\right.$ binding assay)

\begin{tabular}{llll}
\hline Nature of the lesion & $\begin{array}{l}\text { No. } \\
\text { tested }\end{array}$ & $\begin{array}{l}\text { No. positive } \\
\text { (binding } \geqslant 12 \%)\end{array}$ \\
\hline & Healthy adults & 50 & - \\
Control & Degenerative eye disease & 50 & - \\
& Melanocytoma ciliary body & 1 & 1 \\
& Benign iris naevus & 1 & - \\
$\begin{array}{l}\text { Malignant } \\
\text { melanoma } \\
\text { choroid }\end{array}$ & + ve LTT & 10 & 1 \\
$\begin{array}{l}\text { Malignant } \\
\text { melanoma } \\
\text { iris }\end{array}$ & -ve LTT & 12 & - \\
\hline
\end{tabular}

LTT = Lymphocyte transformation test (see Tables 1 and 2).

pared with those in the control group. With 1 exception the serum Clq binding activity in melanoma patients was less than $12 \%$, and therefore the levels were regarded as lying within the normal range (Table 5).

The indirect macrophage migration inhibition test was carried out in only 4 cases of malignant melanoma of the choroid and in 1 patient with iris melanoma. The test was positive in 1 patient with choroidal melanoma and in the patient with an iris melanoma (see Tables 1 and 2).

\section{Discussion}

Both humoral and cellular immunity have been demonstrated in a variety of tumours in man, including malignant melanoma of the skin. It is generally considered, however, that cell-mediated immunity is primarily responsible for tumour rejection in experimental animals, and several reports indicate that a similar mechanism may operate in human neoplasms. ${ }^{37}$

The antigens that elicit this type of reaction appear to be located on the cell membrane and behave as tumour-specific transplantation-like antigens. Since in our experiments, apart from $3 \mathrm{MKCl}$ solubilised membrane proteins, we also used homogenised tumour extract, it can be argued that the stimulatory antigens were of both membranous and cytoplasmic origin. It is possible, therefore, that the responding lymphocytes in these 2 experiments belong to separate subsets.

As humoral immunity has already been demonstrated in malignant melanoma of the choroid ${ }^{938}$ the finding of $T$ cell reactivity to tumour extract raises the question of their respective roles in the host's defence mechanism against such tumours.
Although it is generally agreed that $\mathrm{T}$ lymphocyte mediated immunity is of more significance in tumour control, it is not certain whether the lymphocytes which show increased DNA synthesis (as seen in the present study) represent cytotoxic $T$ cells or helper $T$ cells which co-operate with $B$ lymphocytes in the production of tumour-specific antibodies.

The delayed hypersensitivity skin test remains one of the simplest means currently available for the clinical assessment of the status of cellular immunity in man. Melanoma-associated antigens from allogeneic choroidal tumour extract have been used for the diagnosis of intraocular melanoma. ${ }^{15}$ Whereas $90 \%$ of the patients with histologically confirmed intraocular melanoma gave a positive skin response, about $20 \%$ of patients with nonmalignant diseases also showed a positive reactivity towards melanoma extract. The authors argue that the false positive results may have been due to contamination of the antigenic preparations with normal tissue constituents against which the patients in the control group had been sensitised, but this explanation is equally applicable to those cases which the authors regarded as true positives.

It is now accepted that the skin test as a correlate of cellular immunity has several limitations. Under certain circumstances the delayed cutaneous hypersensitivity may actually be depressed at a time when there is an intense cell-mediated reaction to the same antigen elsewhere in the body. It is known, for example, that in experimental allergic orchitis there may be a depression in skin test reactivity at a time when the test is diffusely infiltrated by lymphocytes. This depression in skin reactivity is evident even when such non-cross-reacting antigen as tuberculin is used. ${ }^{39}$

It is now well documented that a positive delayed skin test is dependent not only on a specific immunological reaction but also on the patient's ability to mount a nonspecific inflammatory response. ${ }^{16}$ The interpretation of abnormal results, therefore, may sometimes be difficult. Furthermore, to determine whether or not the patient has $\mathrm{T}$ cell mediated immunity to the test antigen, the individual should develop a skin reaction consisting of at least $5 \mathrm{~mm}$ or more of induration at the test site $\mathbf{4 8}$ hours after the intradermal injection of the antigen (as is the case in Char's study on ocular melanoma). It should be noted, however, that such a reaction, especially if it is not strong, may not always represent a cell-mediated hypersensitivity because it could very well be a remnant of a previous Arthustype reaction. In addition, the induration which is the hallmark of delayed cutaneous allergy is in fact dependent on vascular leakage and deposition of 
fibrin, ${ }^{40}$ which may be defective in some individuals and in those on anticoagulant therapy. Skin tests are often difficult to quantitate, and often it is not easy to produce an absolutely sterile tumour extract for injection in man, especially with respect to possible contamination with hepatitis $\mathrm{B}$ virus. Furthermore, it may be impossible to exclude a carcinogenic effect of tumour extracts when injected into healthy human volunteers used as controls.

The alternatives to skin testing are macrophage and leucocyte migration inhibition and lymphocyte transformation tests. As mentioned earlier, positive inhibition tests have been reported in choroidal malignant melanoma, indicating that a degree of cellular immunity is present in these patients. The macrophage migration inhibition test (MMT) in which guinea-pig peritoneal macrophages are used may be subject to variation either due to nonspecific reaction of the proteins in tumour extract with the macrophages directly or through the activation of xenogeneic (heterologous) lymphocytes which often contaminate such preparations.

In addition it is well known that some antigens may produce 'toxic' migration inhibition by inhibiting both sensitised and nonsensitised cells. ${ }^{41}$ It has also been shown that migration inhibition tests are most successful when particulate antigens are used. Soluble antigens may fail to cause inhibition of migration even when other tests give a positive cell-mediated reaction. ${ }^{41}$ Negative results should therefore be treated with caution. Migration inhibition studies involving choroidal melanomas should be assessed against this background.

The lymphocyte transformation test (LTT) appears to have an enormous range of application. Whereas the skin test assays predominantly the effector limb of delayed hypersensitivity, which is mediated through a subset of $\mathrm{T}$ lymphocytes known as (TDH), the LTT can detect the activity not only of these cells but also of the helper T cells (TH), which modulate the activity of the antibody producing B lymphocytes. Suppressor T lymphocytes (TS) are also activated during an in-vitro lymphoproliferative response.

Although there are a variety of in-vitro tests to evaluate cell-mediated immunity, the LTT provides a simple and relatively more reproducible and easily quantifiable method. But this technique also has its own limitations. A nonspecific lymphoproliferative response can be induced by the constituents of the culture media as well as the contents of various xenogeneic (heterologous) and allogeneic (homologous) serum products; excessively vigorous handling of lymphocytes may also stimulate T cells. We have therefore used only autologous serum in these experiments. Since the uptake of radioactive thymi- dine increases with the duration of incubation because of exponential cell growth, proper statistical assessment is difficult unless data are normalised, i.e., expressed in such a way that a normal distribution is obtained again. Although the technique of expressing the result as transformation indices rather than absolute counts normalises the data to some extent, it is assumed that the degree of reactivity in the antigen-treated and nontreated culture tubes will be affected by the various variables in the same way and will remain proportional. Unpreventable preincubation stimulation of the lymphocytes may, however, at the same time elevate the response in the control tube and interfere with the reactivity of lymphocytes with the test antigen in the experimental tube. For example, the patient may be allergic to antibiotics used in the culture serum. Fortunately, however, there was no reason to suspect the latter complication in any of the cases in the present study.

Since the lymphoproliferative responses can involve both T and B lymphocytes, the LTT would appear to reflect a wider spectrum of host immunity than either the skin test or the migration inhibition test, these tests depending almost entirely on the reactivity of $T$ lymphocytes.

The lymphoproliferative response to autochthonous and allogeneic extract of malignant melanoma of the choroid were studied in 22 cases of choroidal malignant melanoma. An increased DNA synthesis was demonstrable in 12 of the 21 histologically confirmed cases; in the remaining 4 cases, in which the diagnosis was based on clinical evidence alone, the lymphoproliferative response was negative when using allogeneic tumour extract.

A positive lymphoblastic response to autochthonous tumour extract was also associated with some reactivity towards allogeneic tumour extracts, but the thymidine uptake was comparatively lower in the latter series. This suggests that the response was due to antigens which, although showing features of cross-reactivity, have some element of individual specificity. Whereas it is possible that the response to allogeneic tumour extract was due to histoincompatibility, it would seem unlikely, because the thymidine uptake following treatment with allogeneic tumour extract was never higher than uptake by the lymphocytes when challenged with autochthonous (autologous) extract.

The lymphoblastic response to phytohaemagglutinin (PHA) was normal except in 5 cases in which the response to autochthonous or allogeneic tumour extract was not only poor but showed evidence of a degree of inhibition rather than proliferation. It is tempting to speculate that this was due to the presence of specific inhibitors of mitosis (i.e., 
chalones ${ }^{42}$ ) in the tumour extract, as similar compounds are known to be present in malignant plasmacytoma. ${ }^{43}$ It has also been suggested that autologous serum from cancer patients may have an inhibitory effect on in-vitro lymphoproliferative responses. ${ }^{44}$ While this could account for the relatively low transformation index in some of our patients, ${ }^{45}$ this nonspecific inhibitory influence which is either due to $\alpha$-macroglobulin (KamrinMowbray factor) or to nonspecific binding of antigen to other plasma constituents is usually seen at a serum concentration much higher than that used in the present study. ${ }^{46}$ It has not been possible, however, to exclude the possible inhibitory role of $\alpha$-fetoprotein in these cases. ${ }^{47}$ Furthermore, the invitro immunosuppressive effect of glass-adherent mononuclear cells also could not be ruled out ${ }^{48}$ (Fig. 1), though precautions were taken to minimise the effect of suppressor $T$ cells. In a pilot study it was found that serum from melanoma patients showing a poor response to PHA could also inhibit the lymphoproliferative response in normal individuals. This phenomenon is being investigated in detail. Since it has been suggested that the presence of free antigens or antigen-antibody complexes in patients serum may modify the antigen-specific lymphoproliferative response in tissue culture, attempts were made to detect the presence of such complexes in the serum of the patients in whom lymphoproliferative responses were studied, as shown in Table 4.

The level of circulating immune-complex was within the normal range except in 1 patient in whom the tumour was markedly necrotic. Although raised levels of immune-complexes have been reported in retinoblastoma, ${ }^{49}$ which are invariably necrotic, Dernouchamps and associates ${ }^{50}$ using a different technique found that only 2 of their 7 cases of malignant melanoma of the choroid had any detectable amount of $\mathrm{Clq}$ binding aggregates in the blood. It would appear, therefore, that in malignant melanoma of the choroid at least an immunecomplex-induced tumour enhancement may not be an important feature of its natural history. The reason we used autologous serum instead of fetal calf serum throughout this study was that the latter is known to produce a toxic effect after heat inactivation and may contain a substance which will produce nonspecific stimulation of the lymphocytes. Either effect could obscure any difference in the radioactive uptake counts between the control and the experimental tubes. ${ }^{51}$ Serum from healthy volunteers can be used as a substitute for autologous serum in order to exclude the presence of inhibitors, but this again is not free from problems, because the serum has to be fresh, ${ }^{51}$ and, furthermore, antibodies in the allogeneic serum may react with blood group antigens on the surface of the patients lymphocytes and modify their response to tumour antigens. This limitation would be reduced, however, if the patients studied belonged to blood group $\mathrm{O}$ and therefore lacked group A or B antigens on the cell surface..$^{52}$ Recent studies suggest, however, that immunosuppressive substance present in cancer-bearing animals have a high affinity for lymphocytes, and therefore substitution of autologous serum is unlikely to alter the lymphoproliferative response..$^{53}$ It is of interest in this context that the antigenspecific lymphoproliferative response in cutaneous melanomas is similarly of low key possibly because of weak immunogenicity of melanoma antigens. ${ }^{5455}$

An indirect macrophage migration inhibition test was carried out in only 5 cases of malignant melanoma of the uvea. The test was positive in 2 cases in which the lymphocyte transformation index was also high.

The migration inhibition test appeared to correlate with an in-vitro lymphoblastic response except in 1 patient in whom there was no evidence of lymphokine production in spite of a positive lymphocyte transformation test. Our findings do not compare with those of Manor and co-workers, ${ }^{17}$ who were able to demonstrate a macrophage migration inhibition in 7 of their 8 cases of choroidal melanoma. This may be due to the fact that they used a direct (i.e., 1-stage) migration inhibition test, which is more likely to be affected by nonspecific factors.

The lymphocytes obtained from healthy donors as well as patients with metastatic carcinoma, benign intraocular naevus, and non-neoplastic eye diseases did not show any appreciable reactivity to pooled allogeneic melanoma extract, which further supports the conclusion that the in-vitro nuclear activity seen in melanoma patients was tumourspecific and not due to stimulation by transplantation antigens.

The enhanced in-vitro activity of lymphocytes in melanoma patients correlates well with the extent of the disease, being markedly increased in every case which showed evidence of extraocular extension compared with only 5 of the 14 patients in whom the tumour was localised to the uvea. It is known that the intraocular tissues are not provided with lymphatic channels, so that the afferent limb of the immune response may be prolonged with respect to antigens originating within the eyeball. This may be partly responsible for the immunological privilege enjoyed by the eye and cause delayed sensitisation to intraocular malignancy, in which case the privilege is a disadvantage to the individual. The generally low transformation index in our patients 


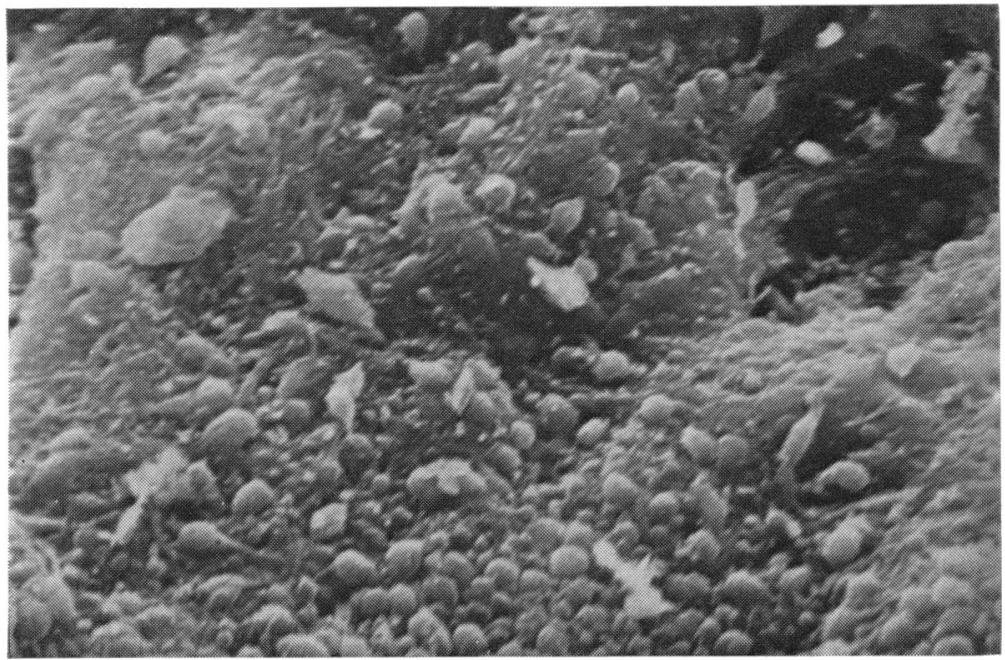

Fig. 4 Scanning electron micrograph of a malignant melanoma of the iris $(\times 516)$. The arrangement of tumour cells is such that during contraction of the iris some of them may detach into the anterior chamber, where they may either become engulfed by the trabecular endothelium or enter the Schlemm's canal to reach general circulation.

should therefore be seen in the light of this background and not compared with tumours arising in other parts of the body, where a low transformation index is usually associated with generalised metastases. ${ }^{56} 57$

The cell-mediated immune response in uveal melanoma appears also to be dependent on the size of the tumour and hence on the amount of antigens available. The lymphocyte transformation test was positive only in those cases in which the largest tumour diameter in contact with the sclera was $12 \mathrm{~mm}$ or more, while in all the negative cases the tumour was $10 \mathrm{~mm}$ or less in diameter apart from 2 cases where it was $11 \mathrm{~mm}$ and $15 \mathrm{~mm}$ respectively. It may also be of significance that in patients with a negative lymphocyte transformation test the tumour consisted of compact spindle cells, while in all the cases with a positive lymphocyte transformation test the tumour consisted of a varying mixture of spindle and epithelioid cells. Since epithelioid cells appear less cohesive, they may more easily become detached and lead not only to early metastasis ${ }^{5859}$ but also to stimulation of the immune system. It is possible that this explanation is not applicable to melanomas of the iris, where tumour cells of both spindle and epithelioid variety or their antigenic components may be released into the anterior chamber during normal contraction and relaxation of the iris (Fig. 4) and pass into the canal of Schlemm either directly or after being taken up by the resident population of phagocytic cells in the trabecular meshwork, which include both histiocytes as well as endothelial cells. ${ }^{60}$

The growth and metastatic property of a malignant tumour is greatly affected by the immuno- genicity of the tumour and the immunological status of the host. ${ }^{61}$ Furthermore, it is known that antigens become more immunogenic after being processed by macrophages. ${ }^{62}$ It is conceivable therefore, that antigenic substances released from a tumour of the iris would have the advantage of having a head-start. This may be the reason why 2 of the 3 cases of malignant melanoma of the iris had possible evidence of sensitisation to tumourassociated antigens as compared to malignant melanoma of the choroid, in which only $45 \%$ of the patients were sensitised. Whether or not this possible early sensitisation is responsible, at least in part, for the slow growth and better prognosis in melanomas arising from the iris remains to be proved.

It is possible that infiltration of the tumour by lymphocytes and plasma cells represents an immune response aimed at eradication of a malignant lesion, such infiltration having been claimed to improve the prognosis in a variety of tumours, including those arising in the breast. ${ }^{63}$ More recently Tritsch ${ }^{64}$ produced evidence that an intense inflammatory reaction at the periphery of cutaneous melanomas reflects a favourable prognosis.

It is significant that all 10 cases giving a positive lymphocyte transformation test showed varying degrees of lymphocytic infiltration in and around the tumour, though it is not known whether the infiltration simply reflected a state of hypersensitivity or represented a favourable prognostic sign. These patients will have to be followed up for several years before any conclusion can be drawn. Histochemical and ultrastructural changes in the infiltrating lymphocytes are indicative of an in-vivo immune reaction, and fewer morphological changes 
have been reported in cutaneous melanomas. ${ }^{6566}$ We are studying the nature of the lymphocytes because it would be interesting to know whether these cells are cytotoxic lymphocytes engaged in tumour homoeostasis or suppressor $\mathrm{T}$ cells that are involved in tumour enhancement. ${ }^{67-68}$

Contrary to an earlier belief, malignant tumours are not truly autonomous, that is, capable of growing relentlessly. Homoeostasis in cancer is now a well recognised entity, and a spontaneous regression of certain tumours such as choroidal melanoma is only one aspect of this important phenomenon. It would appear that a tumour is a heterogeneous and uneven collection of cells, some of which are proliferating (i.e., taking part in the mitotic cycle) and some of which are not, and which is subject to depletion by migration and cell death. ${ }^{70}$ Necrosis is thus not uncommon in choroidal melanoma, and does not always appear to be attributable to ischaemia. $^{14}{ }^{71}$ Theories have been advanced that necrosis and inflammation in choroidal melanoma are indicative of the host's attempt to destroy the tumour. It is of relevance that variable degrees of apoptosis (shrinkage necrosis) and coagulative necrosis were observed in 6 of the 21 cases of uveal melanoma, and, since the lymphocyte transformation test was positive in all of these cases, it is tempting to conclude that the necrosis was immunologically induced. Alternatively, a positive immune response is more likely when a melanoma becomes necrotic and releases large amounts of tumourassociated antigens. Since it is known that tumour cells which infiltrate and produce metastases are different from the primary tumour mass not only in their histological characteristics and karyotypic profiles but also in their susceptibility to cytotoxic drugs due to surface membrane changes and acquisition of stronger electronegative charge, ${ }^{22}$ it is tempting to postulate that in those cases of uveal melanoma in which there was a marked lymphoproliferative response the primary tumour contained a small pre-existing population of cells which was either more antigenic or was capable of extending outside the intraocular environment to mount an immune response.

While this may be true, there is no doubt that infiltration and metastases (in malignant melanoma) are the net results of a variety of cellular characteristics including antigenicity, susceptibility to immune-mediated lysis, anchorage-independent growth, multichromosomal abnormality, and the rate of growth. ${ }^{72}$

The degree of pigmentation and the extent of mitotic activity and their correlation with prognosis have been well documented, ${ }^{59} 7374$ but in our study we did not find any significant correlation between the degree of pigmentation and mitotic activity with the intensity of the lymphoproliferative response. It appears that a positive lymphoproliferative response to melanoma antigens is obtainable in about half of the patients (i.e., 12 out of 25 ) with malignant melanoma of the uvea. However, the lymphoproliferative response evoked by melanoma tissue was much weaker than the response seen in cultures stimulated by PHA and PPD. This may mean that melanoma antigens are poorly immunogenic. The differences between positive and negative responses may be markedly reduced if the antigen is not prepared correctly and the proper culture techniques are not followed meticulously. The best results are obtained when the lymphocyte culture is challenged 24 hours after incubation, since by this time most of the suppressor $T$ cells are ineffective. A good lymphoproliferative response was obtained only when lymphocytes, maintained in a gaseous phase consisting of $5 \%$ carbon dioxide in air, were harvested 6 days after the addition of the antigen. Since the test was negative in about half of the histologically confirmed cases of uveal melanoma, a negative immunological result does not exclude the diagnosis of malignancy. Nevertheless, the fact that we did not obtain any false positive results is encouraging, though the control series consisted of only 12 cases; further work is required before a conclusion is warranted.

It seems that the patients do not mount a reasonable degree of cell-mediated immunological response to melanoma antigens unless the tumour has extended outside the eyeball and become accessible to immunologically competent cells. It is not surprising, therefore, that, although the response of the lymphocytes in these patients was tumourspecific, it was largely ineffective in controlling tumour growth.

This peculiar response of uveal malignancy when compared with malignant tumours elsewhere in the body can be explained at least in part by postulating that both the afferent and efferent limbs of the immune response in the eye may be subject to delay and modification because of the absence of lymphatic channels in intraocular tissues.

We thank Professor A. Garner for his support and Miss L. Hart and Mrs C. Thornton for their secretarial assistance.

\section{References}

1 Newton FH. Malignant melanoma of the choroid. Arch Ophthalmol 1965; 73: 198-9.

2 Ashton N. Primary tumours of the iris. Br J Ophthalmol $1964 ; 48$ : 650-68.

3 Sunba MSN, Rahi AHS, Morgan G. Tumours of the anterior uvea: I. Metastasizing malignant melanoma of the iris. Arch Ophthalmol 1980; 98: 82-5. 
4 Fuchs E. Uber sarkom der aderhaut nebst bemerkungen über nekrose der uvea. Albrecht von Graefes Arch Klin Ophthalmol 1910; 77: 304-92.

5 Jensen OA, Andersen SR. Spontaneous regression of a malignant melanoma of the choroid. Acta Ophthalmol (Kbh) 1974; 52: 173-82.

6 Furth J. Conditioned and autonomous neoplasms. A review. Cancer Res 1953; 13: 477-92.

7 Dunphy EB, Forrest AW, Leopold IH, Reese AB, Zimmerman LE. The diagnosis and management of intraocular melanomas. A symposium. Trans Am Acad Ophthalmol Otolaryngol 1958; 62: 517-55.

8 Anderson B, O'Neil J. Malignant melanoma of the uvea. Arch Ophthalmol 1957; 58: 337-47.

9 Rahi AHS. Autoimmune reactions in uveal melanoma. Br J Ophthalmol 1971; 55: 793-807.

10 Wong IG, Oskvig RM. Immunofluorescent detection of antibodies to ocular melanomas. Arch Ophthalmol 1974; 92: 98-102.

11 Oettgen HF. Immunotherapy of cancer. $N$ Engl J Med 1977; 297: 484-91.

12 Rahi AHS, Garner A, Malaty AHA. Contractile protein antigens in the cells of malignant melanoma of the choroid and their diagnostic significance. Br J Ophthalmol 1978; 62: 394-401.

13 Malaty AHA, Rahi AHS, Garner A. Ostensible antimelanoma antibodies in patients with non-malignant eye disease. In: Silverstein AM, O'Connor GR, eds. Immunology and Immunopathology of the Eye. New York: Masson Press, 1979: 40: 216-9.

14 Rahi AHS. Immunological aspects of malignant melanoma of the choroid. Trans Ophthalmol Soc UK 1973; 93: 79-91.

15 Char DH, Hollinshead A, Cogan DG, Ballantine E, Hogan MJ, Herberman RB. Cutaneous delayed hypersensitivity reactions to soluble melanoma antigen in patients with ocular malignant melanoma. $N$ Engl J Med 1974; 291: 274-7.

16 Johnson MW, Maibach HI, Salmon SE. Skin reactivity in patients with cancer. Impaired delayed hypersensitivity or faulty inflammatory response? $N$ Engl J Med 1971; 284: 1253-7.

17 Manor RS, Livini E, Joshua H, Ben-Sira I. Inhibition of macrophage migration by choroidal malignant melanoma-associated antigens in patients with uveal melanoma. Invest Ophthalmol Visual Sci 1978; 17: 684-7.

18 Pick E. Mechanism of action of migration inhibitory lymphokines. In: Cohen S, Pick E, Oppenhein JJ, eds. Biology of the Lymphokine. London, New York: Academic Press, 1979: 59-119.

19 McCoy JL, Dean JH, Cannon GB, Oldham RK, Herberman RB. Detection of cell-mediated immunity against tumour associated antigens of human breast carcinoma by migration inhibition and lymphocyte stimulation assays. In: Wyhman J, Staquet MJ, eds. Clinical Tumour Immunology. Oxford: Pergamon Press, 1976: 77-86.

20 Field EJ, Caspary EA. Lymphocyte sensitization: an 'in vitro' test for cancer? Lancet 1970; ii: 1337-41.

21 Rahi AHS, Otiko G, Winder AF. Evaluation of macrophage electrophoretic mobility (MEM) test as an indicator of cellular immunity in ocular tumours. $B r J$ Ophthalmol 1976; 60: 589-93.

22 Goldston AH, Kerr EJL, Lorna, Irvine WJ. The macrophage electrophoretic migration test in cancer. Clin Exp Immunol 1973; 14: 469-72.

23 Pritchard JAV, Moore JL, Sutherland WH. Joslin CAF. Evaluation and development of macrophage electrophoretic mobility (MEM) test for malignant disease. Br J Cancer 1972; 27: 1-9.

24 Dale MM, Mongar, J. Role of immunity in diagnosis of human cancer. Br J Cancer 1973; 28 (supp. 1): 237-42.

25 Lewkonia RM, Kerr EJL, Irvine WJ. Clinical evaluation of the macrophage electrophoretic mobility test for cancer. Br J Cancer 1974; 30: 532-7.

26 Crozier EH, Hollinger ME, Woodend BE, Robertson JH. An assessment of the macrophage electrophoretic mobility test (MEM) in cancer diagnosis. $J$ Clin Pathol 1976; 29 : 608-9.

27 Gass JDM. Problems in the differential diagnosis of choroidal nevi and malignant melanomas. Am J Ophthalmol 1977; 83: 299-323.

28 Ferry AP. Lesions mistaken for malignant melanoma of the posterior uvea: a clinicopathologic analysis of 100 cases with ophthalmoscopically visible lesions. Arch Ophthalmol 1964; 72: 463-9.

29 Shields JA, Zimmerman LE. Lesions simulating malignant melanoma of the posterior uvea. Arch Ophthalmol 1973; 89: 466-71.

30 Harry J. Errors in diagnosis. Symposium on management of melanoma of the uveal tract. Trans Ophthalmol Soc UK 1973; 93: 93-102.

31 Jehn UW, Nathanson L, Schwartz RS, Skinner M. In vitro lymphocyte stimulation by a soluble antigen from malignant melanoma. $N$ Engl $J$ Med 1970; 283: 329-33.

32 Meltzer MS, Leonard EJ, Rapp HJ, Barson T. Tumourspecific antigen solubilized by hypertonic potassium chloride. J Natl Cancer Inst 1971 ; 47: 703-9.

33 Lowry OH, Rosebrough NJ, Farr AL, Randall RJ. Protein measurement with folin-phenol reagent. $J$ Biol Chem 1951; 193: 265-75.

34 Carpentier NA, Lange GT, Fiere DM, et al. Clinical relevance of circulating immune complexes in human leukaemia. Association acute leukaemia of the presence of immune complexes with unfavourable prognosis. J Clin Invest 1977; 60: 874-84.

35 Bloch-Stacher N. Hirschhorn K. Stimulation of nonimmunized human lymphocytes by antigen-antibody complexes. Proceedings of the third annual leukocyte conference, University of Iowa. Pieke WO, ed. New York: Appleton Century Crofts, 1969: 557.

36 Federman JL, Lewis MG, Clark WH. Communications: Tumour-associated antibodies to ocular and cutaneous malignant melanomas: Negative interaction with normal choroidal melanocytes. J Natl Cancer Inst 1974; 52: 587-9.

37 Sell S. Tumour immunity. Relevance of animals models man. Hum Pathol 1978; 9: 63-9.

38 Federman JL, Lewis MG, Clark WH, Egerer I, Sarin LV. Tumour-associated antibodies in serum of ocular melanoma patients. Trans Am Acad Ophthalmol Otolaryngol 1974; 78: 784-94.

39 Muir VY, Turk JL, Hanley HG. Comparison of allergic aspermatogenesis with that induced by vasectomy. I. In vivo studied in the guinea-pig. Clin Exp Immunol 1976; 24: 72-80.

40 Colvin RB, Dvorak HF. Role of the clotting system in cell mediated hypersensitivity. J Immunol 1975; 114: 377-87.

41 Thompson RA. Lymphokine production. In: Thompson RA, ed. Techniques in Clinical Immunology. Oxford, London: Blackwell Scientific Publication, 1977: 196-200.

42 Houk JC, Sharma VK, Cheng RF. Fibroblast chelone and serum mitogen (antichalone). Nature (New Biology) 1973; 246: 111-3.

43 Tanapatchaiyapong $P$, Zolla $S$. Humoral immunosuppressive substances in mice bearing plasmocytoma. Science 1974; 186: 784-50.

44 Whittaker MG, Rees K, Clark CG. Reduced lymphocyte transformation in breast cancer. Lancet 1971; $\mathbf{i}$ : 892-3.

45 Knocke J Kanadie A, Powell AE. Modulation of 
lymphocytic responses by factors in human plasma. In Arch Allergy 1974; 46: 584-99.

46 Murgita RA, Tomasi TB, Jr. Suppression of the immune response by alpha feto-protein. II. Effect of MLR and mitogen reactions. $J$ Exp Med 1975; 141: 440-52.

47 Cooperband SR, Nimberg R, Schmid K Mannick JA. Humoral immunosuppressive factors. Transplant Proc $1976 ; 8: 225-42$.

48 Zembala M, Mytar B, Popiela T, et al. Depressed in vitro peripheral blood lymphocyte response to mitogens in cancer patients: The role of suppressor cells. Int $J$ Cancer 1977; 19: 605-13.

49 Char DH, Christensen M, Goldberg L, Stein P. Immunecomplexes in retinoblastoma. Am J Ophthalmol 1978; 86: 395-9.

50 Dernouchamps JP, Vaerman JP, Michiels J, Masson PL. Immune complexes in the aqueous humor and serum. Am J Ophthalmol 1977; 84: 24-31.

51 Oppenheim JJ, Schecter B. Lymphocyte transformation. In: Rose NR, Friedman $\mathrm{H}$, eds. Manual of Clinical Immunology. American Society of Microbiology, 1976: 81-94.

52 Doberson $M J$, Bell AM, Jenson AB, Notkins AL. Detection of antibodies to islet cells and insulin with paraffin-embedded pancreas as antigen. Lancet 1979; ii: 1078.

53 Schumm DE, Billmire DF, Morris HP. Inhibition of mitogen-induced lymphocyte blastogenesis by serum from tumour-bearing animals: changes with tumour growth. Eur J Cancer 1976; 12: 689-94.

54 Nagel GA, Piessens WF, Stilmant MM, Lejeune F. Evidence for tumour-specific immunity in human malignant melanoma. Eur J Cancer 1971; 7: 41-47.

55 Golub SH, Morton DL. Sensitization of lymphocytes in vitro against human melanoma-associated antigens. Nature 1974; 251 : 161-3.

56 Eilhilali MM, Britton S, Brosman S, Fahey JL. Critical evaluation of lymphocyte function in urological cancer patients. Cqncer Res 1976; 36: 132-7.

57 Vanky F, Stjernsnärd J, Nilsonneu. Cellular immunity to human sarcoma. J Natl Cancer Inst 1971 ; 46: 1145-51.

58 Jensen OA. Malignant melanomas of the uvea in Denmark, 1943-1952; a clinical, histopathological and prognostic study. Acta Ophthalmol (Kbh) 1963; Suppl 75: 214.

59 Paul EV, Parnell BL, Fraker M. Prognosis of malignant melanomas of the choroid and ciliary body. Int Ophthal- mol Clin 1962; 2: 387-402.

60 Grierson I, Lee Wr. Erythrocyte phagocytosis in the human trabecular meshwork. Br J Ophthalmol 1973; 57: 400-15.

61 Kerbel RS. Immunologic studies of membrane mutants of a highly metastatic murine tumour. Am $J$ Pathol 1979; 97: 609-22.

62 Nelson DS. In: Nelson DS, ed. Immunobiology of the Macrophage. New York: Academic Press, 1976: 633.

63 Hamlin IME. Possible host resistance in carcinoma of the breast: a histological study. Br J Cancer 1968; 22: 383401.

64 Tritsch $H$. Untersuchungen über Relationen Zwischen entzündlicher Infiltration, Zell type und prognose beim Malignen Melanoma. Arch Derm Forsch 1972; 244: 222-30.

65 Käresen $R$. The immune reaction against malignant melanoma studied in a biopsy material. Acta Path Microbiol Scand 1974; 82: 116-26.

66 Roubin R, Cesarini J-P, Fridman WH, Pavie-Fisher J, Peter HH. Characterization of the mononuclear cell infiltrate in human malignant melanoma. Int $J$ Cancer 1975; 16: 61-73.

67 Fujimoto S, Greene M, Sehon AH. Immunosuppressor $\mathrm{T}$ cells and their factors in tumor-bearing hosts. Suppressor Cells in Immunity: International Symposium. Singhal SK, Sinclair NR, eds. London, Ontario: University and Western Ontario Press, $1975 ; 136-48$.

68 Broder S, Waldmann TA. The suppressor-cell network in cancer (Part 1). N Engl J Med 1978; 299: 1281-4.

69 Broder S, Waldman TA. The suppressor cell network in cancer (part II). N Engl J Med 1978; 1335-41.

70 Weiss L. Dynamic aspects of cancer cell population in metastasis. Am J Path 1979; 97: 601-8.

71 Reese AB, Archila EA, Jones IS, Cooper WS. Necrosis of malignant melanoma of the choroid. Am J Ophthalmol 1970; 69: 91-104.

72 Fidler IJ, Cifone MA. Properties of metastatic and nonmetastatic cloned subpopulations of ultraviolet-lightinduced murine fibrosarcoma of recent origin. Am J Pathol 1979; 79: 633-48.

73 Callender GR, Wilder HC, Ash JE. Five-hundred melanomas of the choroid and ciliary body followed five years or longer. Am J Ophthalmol 1942; 25: 962-7.

74 Rahi AHS, Agrawal PK. Prognostic parameters in choroidal melanomata. Trans Ophthalmol Soc UK 1977; 79: $368-72$. 